\title{
Research and Practice of Hybrid Teaching Mode Based on WeChat Public Platform
}

\author{
Jianqiang Wang* \\ School of information engineering, Yulin University, Yulin, Shaanxi, China \\ 317950860@qq.com
}

Keywords: Hybrid teaching; WeChat public platform; Secondary development; Teaching effect

\begin{abstract}
This paper studies the characteristics of blended learning mode, discusses the characteristics and principles of Hybrid Teaching Based on the WeChat public Platform; the second time development of WeChat public platform is done and the hybrid learning platform based on WeChat is established; finally the effect of blended learning teaching mode based on the WeChat public platform are analyzed; the results show that the model can significantly improve the learner's learning attitude and participation, so as to achieve better teaching effect.
\end{abstract}

\section{Introduction}

At present, blended learning has received the attention of educators, training institutions and enterprises at home and abroad. Especially in recent years, the number of its related research skillfully rising, the content of research and development, in the field of education has also made some achievements. [1,2] The development of network technology and multimedia technology is changing with each passing day, and the research of blended learning has become more and more deeply, and more and more technology products are introduced into education and teaching. WeChat as one of the "dark horse" of technology products in recent years, with hundreds of millions

This paper a of users, has become almost a lot of people's daily life. [3]ttempts to use the existing mature products as an auxiliary platform for the introduction of hybrid teaching oriented mobile terminal, the analysis of the teaching effect of the hybrid learning model on the support of the WeChat public platform. [4,5]

\section{Research on Blended Learning}

After more than and 10 years of research, the concept of blended learning has been expanded and developed. [6] Although there is no authoritative definition of hybrid learning, but from the current domestic and international research point of view, the following points of view are to reach a consensus.

Firstly, blended learning is a combination of the traditional face-to-face learning and online learning (E-Learning or network learning) and the complementary advantages of each other. Secondly, the final goal is to improve the learning performance, to achieve the optimization of teaching effectiveness. Thirdly, blended learning is not only a combination of learning methods, but also the combination of educational theory, educational media and other teaching elements. [7,8,9]

Domestic and foreign experts, the author thinks that blended learning is "from teaching and practice problems of integration of various theories, methods and techniques, [10]the system through classroom teaching and online learning together, and strive to achieve the optimization of the learning process and effect. [11,12]

\section{Research on the Characteristics of Wechat Public Platform}

WeChat is a new mobile application platform products, as of November 2013, WeChat has more than 100 million users, function module as WeChat later added, WeChat public platform has its own advantages and characteristics, enterprises and individuals can set up their own public number WeChat through it. WeChat public platform currently has the function of the main include mass 
push, intelligent reply, user groups, statistical analysis, etc.. The following analysis of its functional characteristics.

The simplicity of the Operation. In operation, the user through the WeChat sweep function, the public number of scanning the two-dimensional code, you can find and subscribe to WeChat public number. Or in WeChat's "add friends" in search and clever reading favorite public number. Administrators need to log on the computer platform, in order to upload material, edit messages, send messages, and manage subscribers. Pressure

Message Push Precision. WeChat public platform to be able to block its users. In the mass message, you can choose the designated group, user gender; the user is located in the region to push messages. For learners of different disciplines background, they can be grouped, push them to the content of interest, so personalized custom point to point, the point opposite the precise content push. Pressure

Accessibility of Information. After the news of the WeChat public platform is sent, the user can receive messages almost simultaneously in the state of the network, and there is very little information to send the message. At the same time, the portability of the phone also allows users to view messages anytime, anywhere. Pressure

The Readability of the Content. WeChat public platform can send text, pictures, voice, video, graphics and text message of the contents of the five categories. Wherein the graphic information can be a single text message that contains only one subject, but also send text messages in the form of a special subject. Each text message can be a combination of text, pictures, video and other forms of media. Users only need to open the public number of messages can be read directly. Pressure

Convenience of Management. In the process of running the public platform, the analysis of the statistical function of the platform can find the problems in time. Such as through the platform of the "user statistics" function, can be changed in a timely manner to the public attention to the changes in the number of users, in order to analyze the reasons for the increase or loss of users. Through the platform of the "picture and text analysis" function,we can clear the situation of each text message is read. The platform administrator can put forward the corresponding solution to the existing problems, and further strengthen the management and maintenance of the platform.

\section{The Construction of Hybrid Learning Assistant Platform}

WeChat learning platform design in the final analysis is based on the WeChat platform for the two designs, especially for WeChat public platform for the two designs. Therefore, WeChat learning platform to fully explore the design of WeChat's own functions and characteristics, on the basis of the need to design and improve the combination of learning. Pressure

Based on the above analysis on the function of WeChat, according to the design principles of the WeChat learning platform, combined with the "embedded system design" curriculum needs, the "embedded system design" WeChat learning platform was designed into the following five modules: resource sharing module, information push module, collaborative communication module, intelligent query module and learning evaluation module.

WeChat platform for the development of learning evaluation, testing the effectiveness of the study provides a powerful support. Firstly, through the WeChat attendance function, timely grasp the student class attendance. Secondly, the use of WeChat voting function to carry out curriculum survey or online testing, real-time grasp of the learning state of the students as well as comments and suggestions to assess the effectiveness of learning and teaching design. Thirdly, through the custom menu to create a learning achievement display window, to provide learners with a special port to show the stage of learning outcomes platform, and read the point of praise as a result of the situation. Lastly, in the micro community to carry out the work of the exhibition, the work of mutual assessment and other learning activities, tracking and recording the activities of learners involved in the situation, the degree of participation as an important part of the formative assessment. 


\section{Results and Analysis}

WeChat public platform to provide a statistical reading statistics function, where the picture is not just pictures and text, but also includes video, audio and Web links and other forms of content. This article from the March 23, 2016 to June 23, 2016. WeChat public platform for reading the data, the number of reading the text, the number of statistics, as shown in table 1.

Table 1 Statistics on the number and frequency of reading

\begin{tabular}{|c|c|c|c|c|c|c|c|c|}
\hline \multirow{4}{*}{ category } & \multicolumn{4}{|c|}{ Reading Statistics [ person] } & \multicolumn{3}{c|}{ Statistics of reading times[ time] } \\
\cline { 2 - 8 } & $\begin{array}{c}\text { Minimum } \\
\text { number of } \\
\text { reading }\end{array}$ & $\begin{array}{c}\text { Maximum } \\
\text { number of } \\
\text { reading }\end{array}$ & $\begin{array}{c}\text { Average } \\
\text { daily } \\
\text { number } \\
\text { of } \\
\text { reading }\end{array}$ & $\begin{array}{c}\text { The total } \\
\text { number } \\
\text { of } \\
\text { reading }\end{array}$ & $\begin{array}{c}\text { Minimum } \\
\text { time of } \\
\text { reading }\end{array}$ & $\begin{array}{c}\text { Maximum } \\
\text { time of } \\
\text { reading }\end{array}$ & $\begin{array}{c}\text { Average } \\
\text { daily } \\
\text { time of } \\
\text { reading }\end{array}$ & $\begin{array}{c}\text { The } \\
\text { total } \\
\text { time of } \\
\text { reading }\end{array}$ \\
\hline Data & 32 & 335 & 112 & 9920 & 127 & 1022 & 302 & 27060 \\
\hline
\end{tabular}

From table 1 we can draw the following conclusions:

WeChat public platform for learning content is widely concerned and read. From the table can be seen in the lowest number of WeChat platform for a day to 32 people, the maximum number of reading for 335 people, the minimum number of reading for 127 times, the maximum number of times to read for 1022 times. In 3 months, the total number of reading up to 9920 people, the total number of reading 27060 times, the average number of reading a day for 112 people, reading up to 302 times. It shows that the learning content of WeChat platform is widely shared by the members of this course, which has attracted the attention of many non-course learners.

The learner will read the learning content of WeChat platform again and again in a day. Through the data analysis, we can see that the number of reading per day is much higher than the number of reading, which means that the same learners in the same day will repeatedly read the course platform of learning content, deepen the understanding of knowledge.

\section{Conclusions}

Through the above analysis of the data, we can get three conclusions: Firstly, learners hold a positive attitude towards learning hybrid WeChat based on the design and organization of the courses given a high degree of certainty, which indicates that the research on blended learning model based on WeChat's construction is valuable and feasible. Secondly, in this blended learning process, whether it is classroom learning or WeChat learning, learners' enthusiasm for learning is very high. Of particular note is the enthusiasm of the learners in WeChat than mutual remonstrance hall, send WeChat platform to provide learners with a more broad space for interaction, strengthen the interaction between learners. Thirdly, through the development of mixed learning, learners can effectively use the system time, improve the cooperative learning ability, independent learning ability, learning efficiency, and better to complete the learning objectives. It can be seen that the application of this blended learning is a successful attempt, and has achieved good results.

\section{Acknowledgements}

This paper is a report of the research project of teaching reform in the Information Engineering Institute of Yulin University.

\section{References}

[1] G. Chinnery: "Going to the MALL: Mobile Assisted Language Learning", J. Language Learning \& Technology . Vol10, No. 1,P. 9-16. 
[2] Lu C, Chang M, Kinshuk, et al: Usability of Context-Aware Mobile Educational Game, J. Knowledge Management and E-Learning. Vol.22( 2011)No.3, p.448-477.

[3] David Parsons: Massey University, New Zealand. Combining E-Learning and M-Learning: New Applications of Blended Educational Resources. Published in the United States of America by Information Science Reference (an imprint of IGI Global).2011.

[4] Russell T Osguthorpe, Charles R.Graham." Blended Learning Environments Definitions and Directions". The Quarterly Review of Distance Education. 2003

[5] Ling Zhang, De-Qun Zhou. A Study on R-TOPSIS Method and Its Application to Web Site Building Alternatives Selection [A]. Proceedings of the 2011 International Conference on Computing, Information and Control (ICCIC 2011 Part2)[C]. 2011

[6] Li ke-dong, Zhao Jian-hua. General Theory and Application Model of Blended Learning. E-education Research. 2004

[7] Liu Cheng-kun. Study of Self-learning Activity Methods of Students Based on Internet Environment. Teaching and Management. 2007

[8] Z.J.Li. The Research on Course Reform of" Modern Education Technology". China Educational Technology. 2009

[9] Armando Fox. From MOOCs to SPOCs, J. Communications of the ACM. 2013 (12)

[10] Ma Dan. MOOC students "high dropout rate ". The Xinmin Evening News. 2013

[11]Jeremy Strayer. How learning in an inverted classroom influences cooperation, innovation and task orientation, J. Learning Environments Research. 2012 (2)

[12]W.H. Liu. Thinking and Practice on the Construction of Signals and Systems Course in Technology Applied University, A. Proceedings of 2016 International Conference on Physics and Physics Education (ICPHY2016)[C]. 2016 